\title{
Editorial
}

\section{Día mundial de la alergia, 8 de julio de 2006}

Las enfermedades prevalecientes en el medio han variado notablemente en las últimas décadas. Hace dos generaciones los padecimientos preocupantes para los médicos, por su alta frecuencia, eran los padecimientos parasitarios y la desnutrición. Una generación después todo el esfuerzo médico se dirigió al estudio de las enfermedades diarreicas y a la deshidratación concomitante. Hoy, los médicos nos vemos abocados a los padecimientos alérgicos, sobre todo cómo prevenirlos y cómo tratarlos.

Las visitas a los médicos por padecimientos alérgicos han aumentado dramáticamente en los últimos años, particularmente en la última década. Este aumento afecta los padecimientos respiratorios (asma, rinitis, conjuntivitis), lo mismo que los padecimientos de la piel (urticaria, eccema atópico) y las alergias desencadenadas por los alimentos. El aumento se observa no solo en la edad pediátrica, sino que también, cada vez aparecen más reportes de aumento en la frecuencia de estas enfermedades en los adultos jóvenes y en la población "madura".

Las causas que se han citado de este aumento han sido varias:

1. El aumento del estrés a que se somete la población infantil:

a. Los niños son sacados a edad temprana de sus casas para estar bajo el cuidado de abuelos, vecinos, maestros.

b. La suspensión precoz de la lactancia materna y la introducción de alimentos alergizantes a edades tempranas.

c. El inicio de la educación formal, altamente academicista, a edades cada vez más tempranas cuando los niños deberían estar en período de aprestamiento.

2. Poca actividad física.

3. Permanecer largos períodos de tiempo en espacios cerrados, tal vez mal ventilados, en contacto con importantes alergenos como el de animales domésticos, ácaros del polvo casero, moho, cucarachas.

4. Permanecer largos períodos de tiempo sentados frente a la pantalla de televisores, computadoras y video-juegos.

5. Ingesta de alimentos altos en sodio, ricos en preservantes, saborizantes y con colores artificiales (comida chatarra).

6. Uso de insecticidas y pesticidas en los productos que servirán de alimento, los mismo que el uso de estos productos en las cercanías de donde se encuentra la población infantil.

7. Avance de la medicina. Se ha considerado que el parto por cesárea, el uso de antibióticos de amplio espectro en la etapa neonatal, el uso de ciertos medicamentos en el embarazo, la aplicación de vacunas preventivas de infecciones que fueron comunes pueden ser factores facilitadores de esta epidemia que tenemos encima nuestro. 


\section{¿Qué debemos hacer?}

Algunas de las medidas que se han recomendado para prevenir la sensibilización alérgica y la evolución de la marcha alérgica antes de que aparezcan todas las posibles enfermedades son:

1. Fomentar la lactancia materna.

2. En la población que tiene antecedentes familiares de atopia posponer la introducción de alimentos alergizantes para después del primer año de vida. Esto incluye no dar fórmulas a base de leche de vaca en esta población en las horas de espera para que baje el calostro de la madre.

3. Evitar la exposición de todos los niños al fumado pasivo.

4. Procurar, en la medida de lo posible, los partos vaginales.

5. Evitar la presencia de mascotas con pelo y plumas dentro de la casa de un niño con parientes atópicos.

6. Retrasar el ingreso de los niños atópicos a la educación formal. Este paso no se debería dar en esta población antes de los 5 años y medio de edad.
Basar el tratamiento de aquellos que tienen sintomatología alérgica en la triada de control ambiental, farmacoterapia y vacunación antialérgica (inmunoterapia o hiposensibilización). El control ambiental bien dirigido puede modificar el curso de la enfermedad y la farmacoterapia es bastante útil para mejorar la calidad de vida de los pacientes pero no deja de ser un tratamiento sintomático. La inmunoterapia también modifica el curso de la enfermedad y es por eso que se les llama vacunas antialérgicas. Su uso evita la aparición de sensibilidades a otras sustancias y además, es el mejor tratamiento preventivo existente para la aparición de asma en aquellos que sufren de rinitis alérgica.

\author{
Dr. José Fernando Chavarría Milanés \\ Jefe Servicio Alergología \\ Hospital Nacional de Niños \\ Asociación Costarricense de Alergología e \\ Inmunología Clínica
}

